Brit. F. industr. Med., 1966, 23, 24.

\title{
Accident Prevention in the Cowshed ${ }^{\star}$
}

\author{
W. MAINZER \\ From Kerem Maharal, Mobile Post-Hof Carmel, Israel
}

Work accidents were studied at two agricultural settlements in the Haifa area. Most of the accidents were caused by farm animals, particularly by cattle, a fact which is in agreement with a general statistical survey conducted by the Department for Occupational Health of the General Federation of Labour in Israel. However, in the present investigation it was found that the accident rate in cowsheds was more than Io times higher among the members of a co-operative smallholders' village (Moshav Ovdim) than it was at a collective settlement (Moshav Shetufi) of the same numerical size. Searching for the basic factors involved, it was discovered that the main reason for this striking difference in accident frequency was the faulty design of the small cowshed at the individual farms of the co-operative settlement, which, lacking adequate protective measures, exposes the farmer to close contact with the animals throughout almost all stages of dealing with them.

It is concluded that accidents from handling cattle can be prevented by adhering strictly to the principle of eliminating direct contact between man and animals in the construction of the cowshed and its annexes.

In this paper an attempt has been made to study some of the factors responsible for accidents connected with the work in cowsheds. Two agricultural settlements in the Haifa area with almost identical features have been investigated. Both settlements are located close to each other with similar climatic conditions, both numbering among their population approximately 160 adult persons engaged in farm work consisting of the same type of work people, mostly immigrants from Central Europe firmly established on the soil for 15 years. Both settlements are based on the same type of mixed farming, producing cattle, poultry, eggs, vegetables, bananas, citrus, and other fruit. The two villages differ, however, in their socio-economic structures, one being a 'Moshav Shetufi' resembling in its organization an industrial enterprise; the other, a 'Moshav Ovdim', is a co-operative of individual smallholders.

There were almost no accidents from the use of farming machinery. Casualties from the overturning of tractors (Rees, 1965) occurred in the neighbourhood on the land of the National Fund but did not involve members of the settlements.

Accidents at the two settlements were caused mainly by farm animals, mostly cattle. Dror (1964),

$\star$ Lecture given at the National Conference on Agricultural Medicine of the Industrial Medical Association in Tel Aviv on November 5, 1964 .

Received for publication February 16, 1965. in an investigation of 563 accidents in 134 cooperative villages in Israel with a population of 20,000 of working age, i.e., an average of 150 workers per settlement, made similar observations (Table I).

TABLE I

Work Accidents in 134 Agricultural Settlements IN I962, ACCoRding to CAUSE (after Dror, 1964)

\begin{tabular}{lcc} 
Cause of Accident & No. of Cases & Percentage \\
\hline Cattle handling & 179 & $31 \cdot 8$ \\
Working implements & 83 & 15 \\
Falls from horsecar & 82 & $14 \cdot 5$ \\
Slips on steep ground & 94 & $16 \cdot 7$ \\
Poison, snakes, stings & 45 & 8 \\
Back strain & 20 & 3.5 \\
Others and unknown & 60 & $10 \cdot 5$ \\
Total & 563 & 100
\end{tabular}

In the present study it was found that the accident rate for cattle handling alone at the individual farms of the co-operative village was more than Io times that at the collective farm. There were no accidents at all from horses at the collective farm, since there the use of draught animals had been abolished, while the individual farmer of the co-operative village still depends on the horse for transportation. Accidents from horses were due, generally, to neglected equipment. A poorly maintained rein, or even a new one of bad quality, would suddenly break, or a damaged shaft would break 
causing the horse to shy and to throw the driver from the cart, resulting in serious injury or death. During the five years 1960 to the end of 1964 , there were 22 accidents from horses ( 14 from falls from the horsecar caused by a shying horse, six from kicks, and two from bites) at the co-operative village.

Table II shows the number of accidents caused by cattle in both settlements during a period of five years.

TABLE II

Number of ACcidents IN THE Cowshed

\begin{tabular}{lcc} 
Year & $\begin{array}{l}\text { Ein-Ajala } \\
\text { (co-operative village) }\end{array}$ & $\begin{array}{l}\text { Nir-Etzion } \\
\text { (collective farm) }\end{array}$ \\
\hline I960 & 7 & I \\
I96I & 5 & I \\
I962 & 5 & I \\
I963 & II & I \\
I964 & I5 & - \\
Total & 43 & 4
\end{tabular}

\section{Accident Study}

A detailed study of the accident records yields the following findings.

Occupation during Accident Most of the accidents in the cowshed happened during feeding (22) or watering the animals (9). Eight of the accidents happened at milking, seven at transport (leading the cow on a rope or chain), and one accident at each of both settlements while assisting the veterinary surgeon. Some work methods responsible for two of the four accidents at the collective farm have been abolished in the meantime. Cows are no longer chained to their places of feeding, and transport has become mechanized.

Immediate Cause of Accident The immediate cause of all the accidents in the cowsheds was violence by the animals attacking the dairy worker, knocking him down by a push with the head or a thrust with the horns, sometimes crushing him to the wall, sometimes kicking him. In two cases the cow stepped on the man's foot, causing injury by sheer weight, in one a fracture. One accident was caused by a stroke with the tail into the eye of the woman who was milking her.

Work Days Lost During five years of observation 844 work days were lost at the Moshav Ovdim and 223 days at the Moshav Shetufi. Statistically, no conclusions could be drawn from these facts since the amount of time lost varied quite considerably with the individual accident. At the settlements one single accident requiring hospitalization or special rehabilitation treatment accounted for 177 out of 223 work days lost at the collective farm and another accident for 270 out of 844 lost days at the cooperative village.

\section{Different Types of Cowshed Design}

To find out the basic reason for the marked difference in accident frequency between the two settlements, it was decided to investigate the safety measures and ways of cattle handling at both places. It was discovered that cowsheds at the smallholder's farm had no protective appliances, so forcing the farmer to out-dated and dangerous methods of cattle handling, whereas cowsheds and buildings for dairy farming at the collective settlement were up to modern standards, and their construction almost obviated accidents. Strangely enough, both plans originated from the same source - the planning department of the Jewish Agency.

The important conception in the buildings of the collective farm is the complete elimination of contact between man and animal. Figure I shows the plan of a unit with accommodation for 80 cows. A wide concrete passage, which runs through the centre of the 40-metre long cowshed accompanied on both sides in its entire length by feeding troughs in the form of half-metre wide shallow trenches, allows for mechanized feeding by a special silo car,

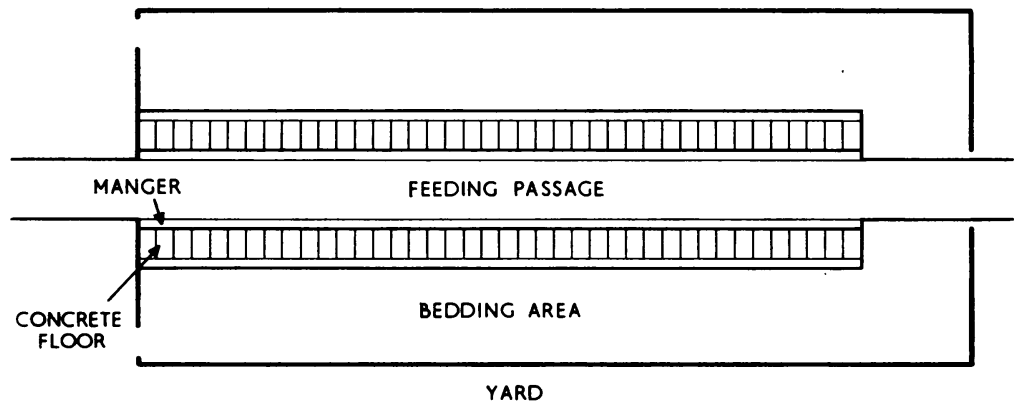

FjG. I. Plan of the cowshed. 


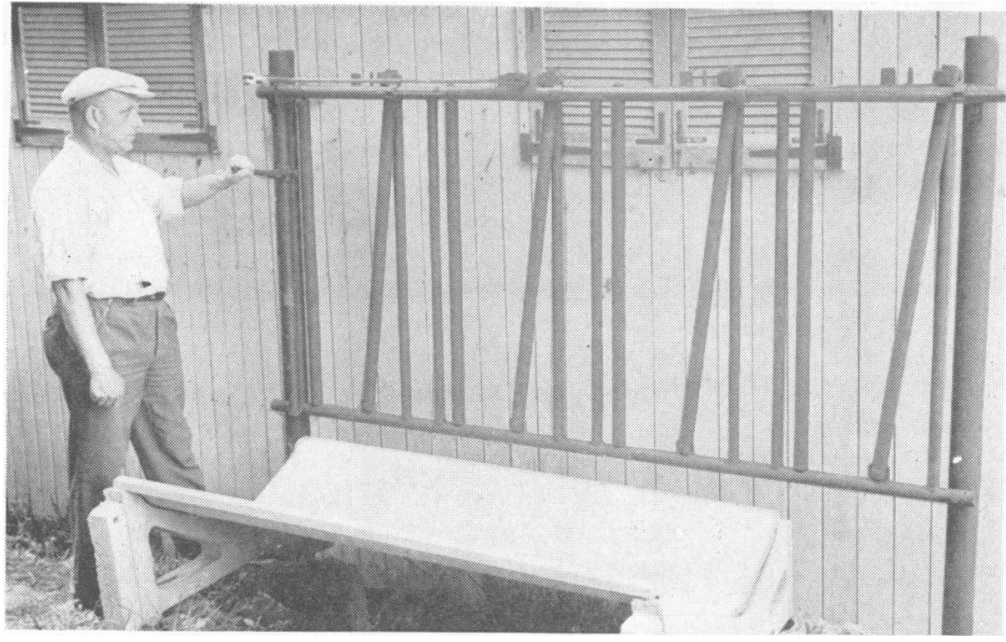

FIG. 2.

Model of versatile stanchion.

Fig. 3. New compact model of Moshav cowshed.

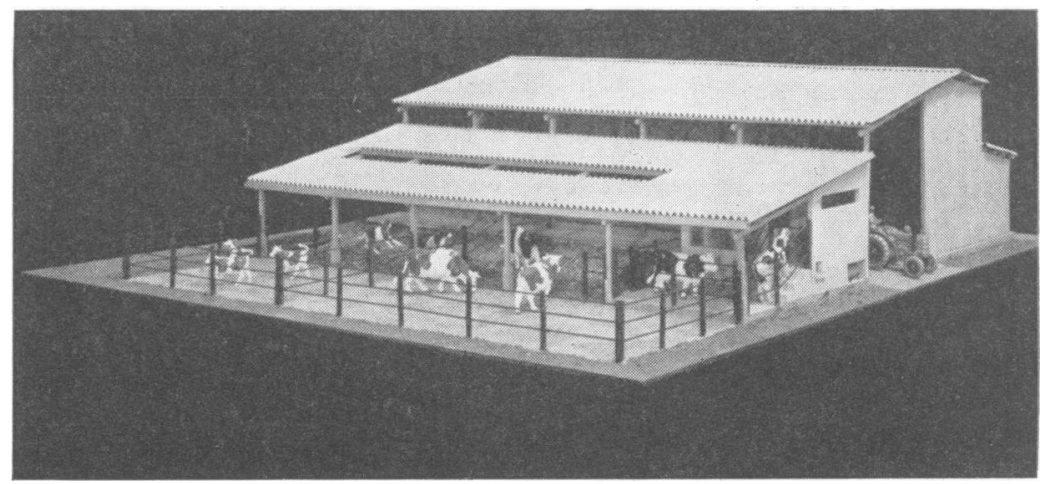

which discharges the food while passing through the building. Behind the feeding troughs and separated from them by a versatile stanchion are 40 partitions on each side. In recent construction these partitions have been abolished, since it was found that the cows do not disturb each other during feeding, though only $25 \%$ of the animals prefer to return to the same place at the trough. The stanchion, which consists of parallel iron staves, usually I-in. ( $25 \mathrm{~mm}$.) water pipes $4 \mathrm{ft}$. (I.22 m.) high, can be opened by manipulating a well oiled iron bar by means of a special lever from outside, thereby shifting the upper part of each third rod towards the next column while the lower end remains fixed in its place by a simple joint (Fig. 2). In this way 40 V-shaped openings are formed, giving every cow ample space to get her head through the grating to reach the food comfortably.

The feeding areas are open at the back, permitting the animals free movement from and to a wide roofed space (bedding area) and from there to a fenced-in yard at both sides of the building. The cows walk by themselves along an enclosure to the milking parlour, where the dairy worker is waiting in a concrete hollow shielded by iron bars against attacks from the animals. All he has to do is to fasten the suckers of the milking machine to the udders of the cows and afterwards to remove them again.

Loading and transportation of cattle, too, are carried out without direct contact between men and animals. A movable platform with an ascending ramp is connected with the loading enclosure and the cattle are driven from outside up into the waiting truck. Restless or resisting steers are given an injection of a tranquillizer before being moved.

These arrangements do not exist at the smallholder's farm. Here, the peasant is exposed to sudden violent action from the animals throughout all stages of handling. A man has to be in close contact with the cattle while feeding or milking, even 
with the help of a milking machine and during loading or transportation. Often he has to lead his cow to the centre of the village on a rope or chain for artificial insemination or veterinary treatment. He drives his small herd to the pasture barehanded with no more than a whip or short stick.

Such is the situation today. Sanitary standards were laid down several years ago (Frank, 1958) but there are still no regulations about accident prevention. The team of engineers of the Rural Building Research Centre at the Israel Institute of Technology in Haifa has been aware of the problem, and a number of excellent new designs have been produced in the meantime (Yalan, 196I; Yalan, Armon, Arnon, Maoz, Sofer, Peleg, and Shagi, 1964). The latest is shown in Figure 3. It is in principle a compact model of the large cowshed at the collective farm with places for 15 to 20 cows and containing under the same roof a hay barn, milking parlour, and space for heifer and bullock rearing and fattening. Ideal with regard to safety and economy in labour and food, its shortcoming is the cost, which amounts to Ifr. $£ 25,000$, an investment which the average small farmer here cannot afford.

One further safety device deserves mention. This is an improved method of mechanical closure which can be installed at slight cost in existing cowsheds.
Its construction enables one or more places at will to be opened simultaneously, thus allowing the animals to reach their food, but at the same time restraining them by the head so restricting their movements and lessening the chance of an attack.

The author wishes to thank Professor E. Yalan, Eng. A. T. Sofer, and Y. Arnon, of the Rural Building Research Centre at the Israel Institute of Technology, Haifa for their technical advice and kind assistance with the illustrations, and Mr. A. Rotfeld of Nir-Etzion for expert information on cattle handling.

\section{REFERENCES}

Dror, K. (1964). Work Accidents at Agricultural Settlements. Report at the National Conference on Agricultural Medicine, Tel Aviv (in Hebrew).

Frank, S. (1958). Manual for Cowshed Sanitation. Ministry of Health, Jerusalem (in Hebrew).

Rees, W. D. (1965). Brit. med.F., 2, 63.

Yalan, E. (196r). Private and Co-operative Agricultural Settlement Planning. International Seminar on Rural Planning. Dept. for International Co-operation, Ministry of Foreign Affairs, Haifa.

-, Armon, Y., Arnon, Y., Maoz, Y., Sofer, A., Peleg, A. D., and Shagi, R. (1964). Efficiency in the Construction of the Cowshed at the Co-operative Settlement. Rural Building Research Centre, Israel Institute of Technology, Haifa (in Hebrew). 